\title{
Urban green space recreational service assessment and management: A conceptual model based on the service generation process
}

\author{
Jialin $\mathrm{He}^{\mathrm{a}, \mathrm{b}, \mathrm{c}, *}$, Hongmei $\mathrm{Yi}^{\mathrm{d}, \mathrm{e}, \mathrm{b}}$, Jian Liu ${ }^{\mathrm{b}}$

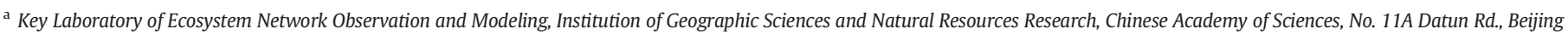 \\ 100101, China \\ b United Nations Environment Programme-International Ecosystem Management Partnership (UNEP-IEMP), No. 11A Datun Rd., Beijing 100101, China \\ c University of Chinese Academy of Sciences, No.19A Yuquan Rd., Beijing 100049, China \\ ${ }^{d}$ Center for Chinese Agricultural Policy, School of Advanced Agricultural Sciences, Peking University, Beijing, 100871, China \\ e Center for Chinese Agricultural Policy, Institute of Geographic Sciences and Natural Resources Research, Chinese Academy of Sciences, No. 11A Datun Rd., Beijing 100101, China
}

\section{A R T I C L E I N F O}

\section{Article history:}

Received 15 June 2015

Received in revised form 12 December 2015

Accepted 31 January 2016

Available online 27 February 2016

\section{Keywords:}

Urban green space

Recreational service

Efficiency

Equity

Public health

Urban land use planning

\begin{abstract}
A B S T R A C T
The current understanding of urban green space (UGS) recreational service is limited due to the lack of being examined under the logic that underlies the ecosystem service paradigm, leading to limitations in the application of ecosystem based management in urban land use planning. This paper offers a conceptual model of UGS recreational service that follows the logical flow of ecosystem service generation, supplementing the knowledge gap and supporting the use of ecosystem base management in urban land use planning. The model includes four categories; UGS features, population characteristics, recreational use behavior, and recreational benefits while considering the use behavior as the service carrier. A process analysis shows the role of each model component in generating the services, and highlights the important role of regulating service potentials and their mobilization. Ways of informing interventions for improving efficiency or equity have been suggested. Efficiency can be assessed by applying the dose-response mechanism in the model. Equity on the other hand, can be measured by exploring which predictors of use are dominant, which advances UGS access assessment by shifting from the spatial-based to the use-based. Survey design techniques and indicators measuring various variables of the model have also been proposed.
\end{abstract}

(c) 2016 Elsevier B.V. All rights reserved.

\section{Introduction}

The ecosystem service paradigm has been evolving and shaping research and application for years. The current interest in ecosystem services was stimulated by the widely acknowledged Millennium Ecosystem Assessment (MA, 2005) as well as the study on the Economics of Ecosystem and Biodiversity (TEEB, 2010). This expansion of interest triggered the use of ecosystem services as a "common language" for ecosystem-based management (Granek et al., 2010). As an integrated approach that considers the interconnected nature of ecosystem, ecosystem based management aims at maintaining ecosystems in a healthy, productive and resilient condition so that they can provide the functions, goods and services that enrich and sustain human wellbeing (Kappel and Martone, 2011). Focusing on ecosystem services assessments can facilitate comparisons in management alternatives by linking these management actions to changes in ecosystem conditions

\footnotetext{
* Corresponding author at: Institution of Geographic Sciences and Natural Resources Research, Chinese Academy of Sciences, No. 11A Datun Rd., Beijing 100101, China.

E-mail address: jialin.he@unep-iemp.org (J.He).
}

and to an understanding of how those changes could affect the benefits that human derive from ecosystems (Granek et al., 2010).

Within the ecosystem service paradigm, the importance of socio-economic relevance has gradually been receiving attention (Spangenberg et al., 2014). This is important for cultural services because they have strong linkages to human perceptions, attitudes and beliefs (Chan et al., 2012; Wallace, 2007) and require further human activities for service provision and subsequent benefit generation. In the process of understanding provisions from cultural services, economics and social science are as important as ecology (Milcu et al., 2013).

As a cultural service, urban green space (UGS) recreational service has not been systematically examined under the ecosystem service paradigm (Fish, 2011), although many opinion pieces, reviews and conceptual models currently exist. The term "recreational service" is relatively new and has emerged in conjunction with the rising interests in ecosystem services. As a matter of fact, a range of publications have partially overlapped with the concept of UGS recreational service, yet they do not use the terminology related to ecosystem service, nor do they try to examine such service under the ecosystem service framework. Examples include studies on landscape preference (Hagerhall et al., 2004; 
Ode et al., 2009), environmental justice (Byrne et al., 2009; Matthew McConnachie and Shackleton, 2010), active living (Evenson et al., 2013; Giles-Corti et al., 2005) and environment-health relationships (Villeneuve et al., 2012; White et al., 2013). The ideas that these publications present are quite implicational and provide direction on how the service is essential in supporting human health and well-being.

Looking at the case of UGS recreational service under the ecosystem service paradigm would generate an integrated socioeconomicecological model, and such model can help support the assessment of the service via the use of indicators derived from multiple disciplines. To adopt ecosystem based management in urban land use planning is to show the linkages between land use changes and a variety of ecosystem services and benefits (of which UGS recreational service is included). Such information can provide valuable insight to decision makers. Without such a tool, the conduction of the service assessment would be constrained, leading to an insufficient understanding and thus impeding the integration of ecosystem based management into the process of urban land use planning.

Considering the various health and well-being benefits that UGS provides (Hartig et al., 2014), the setting of UGS is expected to lead to cost savings in health care (Carpenter, 2013; DTLR, 2002), and thus should be seen as a critical component in urban land use planning. For example, a pioneering study in the UK has shown that the potential economic implications of UGS from encouraging outdoor physical activity would be more than $£ 1.8$ million a year (Bird, 2004). However, the influencing factors of UGS recreation and its benefits vary from place to place. If we want to develop interventions that are successful in practice, it is crucial to know what factors underpin the UGS recreation, to what extent the benefits exist, and how efficiency in generating the benefits can be achieved. To answer these questions, assessment of the service would be needed.

Another key concern during the urban land use planning process is the issue of equity. How can equity in UGS access be assessed and improved? The current measure of equity in UGS access has been the mapping and analyzing the spatial distribution of UGS and then linking this with spatially referenced socioeconomic characteristics (Comber et al., 2008; Dai, 2011; Landry and Chakraborty, 2009; Matthew McConnachie and Shackleton, 2010; Wolch et al., 2005), which is believed to be quite limited and may leads to insufficient results of assessment. Firstly, access refers to the empowerment of an individual to use the service, and as a concept, it summarizes a set of dimensions describing the degrees of fit between service provider and individuals (McIntyre et al., 2009; Penchansky and Thomas, 1981). Spatial availability is only one sub-item of the complex concept of access, and thus can rarely represent it. Secondly, the spatial-based measure may not fully capture the information needed from either supply side (i.e. UGS) or demand side (i.e. potential visitors). UGS is not an "average" land use form (it differs in types, range of facilities or perception of safety) (Wheeler et al., 2015), and it may be of differing significance among population subgroups (e.g. gender difference (Thompson et al., 2014)) meaning that the potential visitors are not "average" people. More comprehensive way of measuring is needed.

The goal of this paper is to develop an evidence based conceptual model of UGS recreational service generation and delivery under the ecosystem service paradigm. It takes a closer look at the factors contributing to the use of UGS, allowing for biophysical and socio-economic relevance involved, and outlines the derived recreational benefits. The roles of each model component in generating UGS recreational service are elaborated and indicators that measure these components are recommended. Moreover, how the model can be used to serve management objectives such as efficiency and equity have also been suggested. In general, the paper has three contributions; first, it enriches the knowledge of UGS recreational service by adapting the case of UGS recreation to the ecosystem service cascade model; second, it supports the use of ecosystem based management in the process of urban land use planning by guiding the assessment of efficiency and equity in UGS recreation; and lastly, it proposes a way of assessing equity, which advances the current measure by shifting from the spatialbased measure to the use-based.

The remaining sections are organized as follows: Section 2 synthesizes the evidence supporting the relationships among components of the model. Section 3 outlines the structure and rationale of the model. Section 4 elaborates ways of the service assessment with aims of efficiency and equity. Section 5 discusses issues in relation to conduction of empirical studies. Finally, Section 6 concludes the paper.

\section{The State of the Art Knowledge}

\subsection{The Ecosystem Service Cascade Model}

The logic that underlies the ecosystem service paradigm represented by the cascade model offers a way of classifying different steps of generating ecosystem services from ecosystem to human well-being (Haines-Young and Potschin, 2010; Potschin and Haines-Young, 2011). The cascade model, since it was first introduced by Haines-Young and Potschin (2010), has been adapting and improving. In the most recent version of the model (Spangenberg et al., 2014), the roles of socioeconomic processes have been reinforced. It recognizes the chain of "function-service potential-service-benefit" as the links of ecosystem service generation, and highlights the roles of socio-economic processes in leading from one level to the next on the cascade. Here the term "function" strictly refers to the biogeochemical characteristics of ecosystems, including the structures and processes. The model suggests that an ecosystem function can be turned into a service potential as long as the potential usability of certain biophysical structures are being recognized. The service potential can then be mobilized to provide service with additional inputs such as investment of labor, time, resources and possibly money. Once this flow has been understood, management interventions targeting the maintenance or increase in service benefits can be derived by enhancing service potentials and their mobilization.

\subsection{Existing Conceptual Models}

In the ecological health paradigm, the conceptualization of the natural environment has been steadily reflected in a number of conceptual models. A review of typical ecological health models (Coutts et al., 2014) has pointed out the relationship between natural environment and health "evolved from undynamic environment to a more sophisticated understanding of ecological interactions". For example, the roles of socioeconomic and natural environments are seen as equally significant in influencing health in the Butterfly Model of Health (VanLeeuwen et al., 1999). The Public Health Ecology Model (Coutts, 2010) advances the role of natural landscape as supporting health directly through environmental agents and indirectly through the behaviors that the environment facilitates or hinders. The Transformation via Balanced Exchange Model (Coutts et al., 2014) depicts the exchange of ecosystem services and human actions between natural and human systems, of which human health is among the outcomes of these interactions. With more relevance to the concept of ecosystem service, the conceptual framework integrating green infrastructure, ecosystem and human health (Tzoulas et al., 2007) highlights numerous dynamic factors and their complex interactions affecting ecosystem and human health in urban areas. It regards the green infrastructure and related improvements in ecosystem health as providing the environmental settings for public health, and at the same time, these environmental settings are affected by public health.

Efforts in understanding the environment-health relationship have also been made within the ecosystem service paradigm. Clark et al. (2014) have examined the indirect relationship between biodiversity and human health, through cultural pathways. It has been shown that biodiversity change will affect provision of cultural goods, the 
opportunities to realize the cultural value placed upon these goods, and thus human well-being and health.

There have also been some attempts in trying to conceptually summarize issues related to the use of UGS. Byrne and Wolch (2009) appreciated the historical, political-economic and socio-ecological processes as factors shaping park space and behaviors in their use. In their model, the feature of park space and characteristics of potential users formulate people's perceptions, and it is these perceptions that shape people's choices in using parks. By examining visitors' reasons for the use of UGS, Irvine et al. (2013) generated a taxonomy of motivators (personal purpose, environment attributes and park features), and linked these motivators to six categories of benefits (global, physical, cognitive, affective, social, spiritual). Bedimo-Rung et al. (2005) examined the roles of parks in public health. The model shows park use behavior as a two-stage process (i.e. park visitation and physical activity within park), regards user and park characteristics as antecedents of the use behavior, and summarizes five dimensions of benefits derived either from the use behavior or directly from park characteristics. It privileges park characteristics over personal variables in terms of the strength in changing park use behavior. Specifically, park characteristics are composed of six conceptual aspects (features, condition, access, esthetics, safety and policies) operating through four geographic areas (activity areas, supporting areas, overall park and surrounding neighborhood) to support physical activity within parks, while user characteristics including sociodemographic variables are regarded as immutable.

Models from ecological health and ecosystem service paradigms mentioned above conceptually represented the relationship between nature and human health, and, to some extent, reflected on the associations between UGS and its major derived benefits - human health. However, the models do not, nor were they meant to, explicitly depict how these health and well-being benefits are obtained through recreational pathways. On the other hand, the extant models associated with the use of UGS explains UGS use behavior from different angles, giving a holistic understanding of the issue at an explanatory level, yet challenges remain in terms of how to integrate these conceptualizations into practice and to allow them to be transferred into a language that policy makers understand, i.e. going beyond the explanatory level to a policy-relevant level.

\subsection{Health and Well-Being Benefits in Relation to UGS}

There is an expanding research exploring the health benefits of contact with UGS, and more broadly "nature", using different methodologies and conceptualizations. In a review of the benefits of interaction with nature, Keniger et al. (2013) have constructed a typology of potential benefits of people-nature experiences, which include psychological, cognitive, physiological, social, spiritual and tangible benefits. Generally speaking, contact with nature can promote human health and wellbeing. Although the effects are small in comparison to other factors such as income, education and smoking, a small beneficial effect can make a large contribution to population health based on a large number of people. This conclusion is made by Hartig et al. (2014) after a comprehensive analysis of 59 relevant reviews. It has been further indicated that the evidence for some benefits, such as short-term affect, cognition and physiology effects, have been fairly well established in laboratories and field experiments. However, a large portion of the evidence at population level is still correlational due to the dominance of cross-sectional designs in the research of long-term health outcomes. Firm causaleffect conclusions could not be drawn. Therefore, population-level quasi-experimental studies have been suggested as a priority of future research (Hartig et al., 2014).

Understanding how the relationship between nature and health occurs can assist interventions that promote potential benefits. Four pathways for delivering these benefits have been refined, including air quality, physical activity, social cohesion, and stress reduction (Hartig et al., 2014). These pathways emphasize different aspects of nature, either as physical environment, settings for behavior or experiences, and they usually function simultaneously (Hartig et al., 2014).

If we consider competing priorities for funding in health care, doseresponse mechanism needs to be taken into account (Hartig et al., 2014). Drawing upon a commonly used approach in health science, the idea of dose-response in nature-health relationships explicitly probe how much "doses" of nature are needed to generate possible benefits at the lowest cost. Three aspects of the "nature dose" have been proposed (Shanahan et al., 2015), encompassing intensity, frequency and duration of nature exposure. The quality and quantity of nature elements can provide useful measures of "intensity", the number of times and pattern a person is exposed to nature (cyclic, random or intermittent) can be used to stand for "frequency", while the length of time a person is exposed to a nature element represents "duration". As for health response to nature, it has been pointed out that a low appreciation of the variety of health outcomes may lead to mischaracterization of the evidence base (Hartig et al., 2014). It has been suggested that the intermediate health-related outcomes, such as amount of physical activity, changes in physiological activity and/or in emotional states, should to be distinguished from final health outcomes, i.e. disease states or measures of mortality (Hartig et al., 2014). Furthermore, attention should also be paid on the time scales relevant for health effects which have the potential to be immediate or delayed or disappear over time (Hartig et al., 2014; Shanahan et al., 2015).

\subsection{Correlates of Recreational Behavior}

Recreational behavior is a key midway of nature function to enhance human health and well-being. Correlates of recreational behavior patterns have been mainly understood from environmental and personal dimensions. Similar to the issues existing in nature-health studies, a majority of the recreational behavior research is cross-sectional and thus less robust to draw a casual-effect conclusion.

Regarding the environmental correlates, the focus has been on the availability or proximity of UGS, or on a set of UGS quality features. Studies have found that people living in a greener environment (Cohen et al., 2006; Coombes et al., 2010; Ellaway et al., 2005; West et al., 2012) or living closer to large UGS such as parks (Cohen et al., 2007; Coombes et al., 2010; Giles-Corti et al., 2005) are more likely to be physically active. Result from a natural experimental study in the U.S. has demonstrated that people's activity levels can be enhanced by greening neighboring vacant lots (Branas et al., 2011). However, proximity, in some contexts, may be less important in explaining use (Schipperijn et al., 2010a). This might be due to the significance of proximity needs to be derived from its correlation with the quality characteristics such as conduciveness to physical activity (Nielsen and Hansen, 2007).

Types of UGS have been found to be associated with levels of physical activity in children (Lachowycz et al., 2012). Potentials of compensation in recreational behavior among different types of UGS don't seem to be obvious. For example, a study in Sweden has found that people do not compensate for lack of neighborhood UGS with visits to distant large UGS (Grahn and Stigsdotter, 2003), and the result from an Australia study has shown that yard use does not compensate for park use (Lin et al., 2014).

Various aspects of UGS quality have been considered in relation to the use of UGS. For example, physical activity levels have been found to be positively related to the presence of certain elements (such as water body, wooded areas, birdlife, walking paths, children's play equipment, public toilets, picnic tables, lighting and parking lots (Giles-Corti et al., 2005; Schipperijn et al., 2013)), level of maintenance (such as presence of litter (Dallimer et al., 2014)), plant richness (Adinolfi et al., 2014) and restorative properties (Hug et al., 2009). The conclusion of casual-effect relationship drawn by natural experiment studies have indicated that the use of UGS can be increased by establishing elements such as playgrounds, walking tracks and/or barbecue areas (Veitch et al., 2012), as well as improving sanitary 
conditions or the appearance and safety of vegetation (Thompson et al., 2014). The underlying reason has been inferred as that UGS with good quality is able to reduce an individual's perception of effort and increase motivation and intention to repeat the activity (Gladwell et al., 2013).

There have been attempts in trying to decompose the general concept of quality into several specific aspects, expressed by various wordings such as quietness, facilities, naturalness, diversity, livability, safety, esthetics, amenities, maintenance and condition (Lee and Maheswaran, 2011; McCormack et al., 2010; Smith et al., 1997; Van Herzele and Wiedemann, 2003). To summarize the various overlapped wordings, Tveit et al. (2006) have developed a nine-concept framework to indicate subjective visual quality of landscapes; they are stewardship, coherence, disturbance, historicity, visual scale, imageability, complexity, naturalness, and ephemera. Indicators operationalizing those aspects have also been recommended (Ode et al., 2008). A recent effort of linking park quality and its use patterns has been to assess the "structural diversity" of UGS from biotic features (including tree/forest aspects and ground vegetation), abiotic site conditions (including water elements and topography) and infrastructure dimensions (including facilities for active recreation, relaxation and amenities) (Voigt et al., 2014). This multi-dimensional assessment approach assumes that people perceive UGS biotic features on a structural level (not species level) and thus it used a structural level tool regarding visually dominant features. The two frameworks classify quality by perceptions of physical and social environments, and thus mainly rely on observer assessments.

Other attempts have been made to link objective measures of UGS quality (such as density of UGS types, plant, butterfly and bird species richness (Dallimer et al., 2012; Fuller et al., 2007; Wheeler et al., 2015)) with human health and well-being. However, potentials of discrepancy between the objective measures and the important perceived measures pose a challenge in explaining the use of UGS accurately (Dallimer et al., 2012).

In terms of personal factors influencing the use of UGS, most of the emphases have been on socio-demographic and socio-economic characteristics, including gender, age, ethnicity, education, occupation and income (Byrne et al., 2009; Cohen et al., 2007; Thompson et al., 2014; Ward et al., 2010). For example, UGS has been found to be more important to women than men in Scotland, due to differences in their ways of responding to the environment (Thompson et al., 2014). In South Africa, most of the visitors to the botanical gardens were white, middle to old aged, well educated professionals with medium to high incomes, who were not demographically representative of the general local population (Ward et al., 2010). However, this is not always the case, an UK study has shown that income, age and gender were not predictors of the visit frequency (Dallimer et al., 2014). Additionally, in recent years, researchers have begun to explore the topic from a psychological point of view. Infrequent users were more likely to state motivations associated with the quality of UGS, while frequent users gave motivations pertaining to physical, repeated activities, reported by an UK study (Dallimer et al., 2014). In Australia, individuals' nature orientation has also been found to be the primary determinant of park visitation (Lin et al., 2014). Publicity and activities to encourage knowledge of UGS has been found to be potential ways of promoting use (Thompson et al., 2014).

Moreover, some studies have considered the topic reversely, i.e. listing personal barriers that impede the use of UGS. These barriers include factors that are likely to limit mobility (being overweight, too old, injury or disability), lack of time, lack of information and not enjoying exercises (Byrne and Wolch, 2009; Lee and Maheswaran, 2011; Schipperijn et al., 2010b).

An important intrinsic character of the relationship that should not be ignored is the context-specific nature. Variety among cultures, geographic regions and socio-economic groups in the use of and response to nature with different characteristics remains underexplored (Hartig et al., 2014; Keniger et al., 2013), and this is why the context-based assessments are needed.

\section{The Conceptual Model for UGS Recreational Service Generation and Delivery}

This paper defines its discussion on UGS recreation within the scope of experiencing or being in nature through direct intentions, and experiencing nature while not being physically present in it or as a byproduct of another activity are not belong to our discussion (Keniger et al., 2013). Being aware of this, we use the adapted ecosystem service cascade model (Spangenberg et al., 2014) as a logic guide to develop the conceptual model for UGS recreational service generation and delivery (hereafter referred to as "the model", as shown in Fig. 1). In order to be capable of guiding conduction of assessment and to be informative on generating interventions, two criteria have been adopted during the development of the model: 1 ) the classification of the model's components should be policy-relevant, i.e. every component in the model should be clear in terms of whether it can be modified by interventions, and the importance of the components that can be modified should be weighted, and 2) all the variables need to be measurable so that clear indicators can be developed.

Fig. 1 shows the model. It is proposed based on a wide range of publications covering case studies, opinions, reviews and conceptual models from different disciplines. It encompasses UGS features, population characteristics, recreational use behavior and recreational benefits as four categories. The hypothesized relationships among them are indicated by the arrows. Boxes and arrows in red are used to indicate the role of each component in generating the service. Left-to-right reading tells us the process of generating recreational service, while reverse reading would inspire us with potentials of developing interventions.

\subsection{UGS Features and Population Predisposition - The Service Potential}

UGS features are considered as the biophysical structure which are the raw materials contributing to the provision of recreational service. When people recognize the potential usefulness of a certain UGS features to their respective circumstances, the recreational service potential is therefore generated. This recognition process "can be characterized as an intellectual act defining a service potential, and as a potential supply for an assumed societal demand (Spangenberg et al., 2014)". We hypothesize that the process can be influenced by population predisposition characteristics. The more fit the biophysical structure with people's needs, the higher level of service potential will be generated.

\subsubsection{UGS Features}

UGS has different types, and main ones include parks, community gardens, roadside green areas, and woodlands or farmlands in and around the cities. These UGS types are perceived and used in different ways. Literature has shown that aspects of quantity, distribution and quality play roles in the use of UGS (see Section 2.4 for details). When describing UGS features, these aspects of UGS as a whole or as specific types need to be considered.

The quantity aspect refers to the amount or size of UGS as well as the composition of its elements. Constituent elements of UGS include vegetation, water body, built environment (paths, seats \& shelters, garden ornaments, public toilets, parking lot), recreational facilities (exercise facilities, kids play settings), as well as recreational programs undertaken within. Different types of UGS vary in terms of their combination of elements.

Distribution describes the pattern of UGS located in urban areas. The combination of distribution and quantity aspects helps to shape UGS spatial availability for populations (Zhang et al., 2011), which is of great importance to individuals' decision making on choosing site and time. 


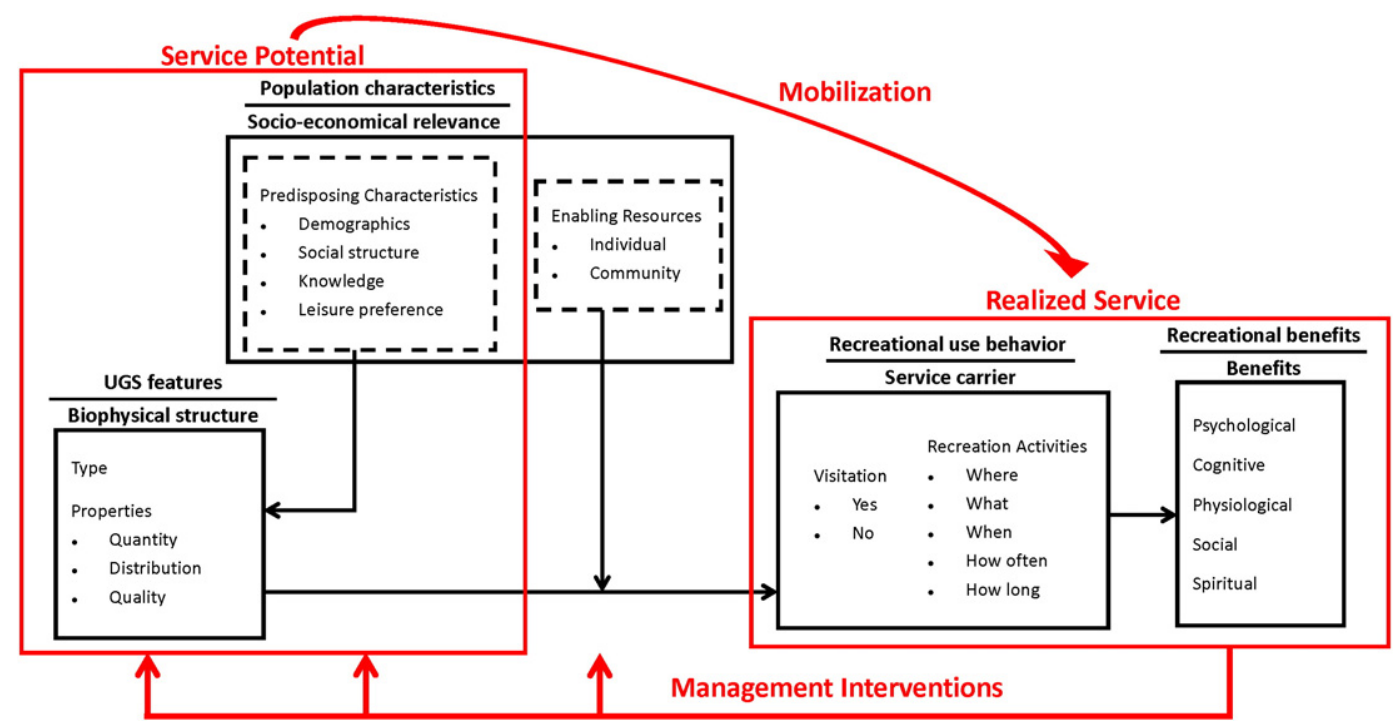

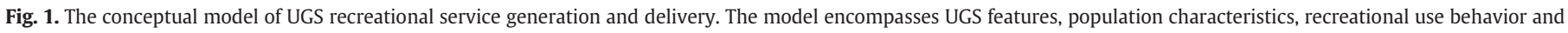

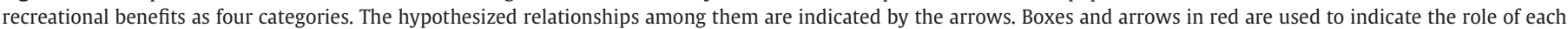

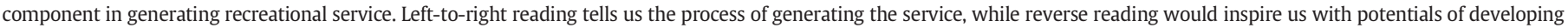
interventions.

UGS is not just a structural aggregation of its elements, but a holistic system where elements are functionally related to each other (Van Herzele and Wiedemann, 2003). Quality aspect is used to reflect how well the UGS is designed and maintained. Literature has shown several attempts trying to decompose the general concept of quality of UGS/ community environment/landscape/nature, serving to varied interests (see Section 2.4 for details). When exploring relationship between UGS quality and its use, we suggest to use a combination of the structural diversity (based on biotic, abiotic and infrastructure aspects (Voigt et al., 2014)) and stewardship as major aspects. The structural diversity framework not only covers a majority of the sub-concepts describing UGS quality, but also offers a way of mapping them, and thus it could facilitate the comparison of different UGS. It is based on UGS visually dominant features instead of pure biodiversity measures and thus it could avoid flaws generated by the mismatch between the objective measured UGS quality and people's perceptions. Stewardship refers to the sense of order and care presented in UGS (Tveit et al., 2006). Poorly maintained environment, such as places being abandoned or scattered with litter, is able to generate people's fear of crime (LaGrange et al., 1992) and feeling of being threatened (Brower et al., 1983), and therefore influence its use.

\subsubsection{Predisposing Characteristics}

The predisposing component includes characteristics that describe the predisposition of individuals to use of UGS. These include demographic factor, social structure, knowledge, and leisure preference.

Demographic variables such as age and gender represent the biological imperatives that suggest the likelihood that an individual will need UGS recreation. Social structure characteristics, such as education, occupation, cultural background, religion and income, suggest what the life style of the individual may be, and point out the physical and social environment of individuals and the associated behavior patterns related to the use of UGS.

Knowledge refers to awareness of the recreational benefits provided by UGS, as well as the benefits of being physically active. Higher levels of awareness might generate higher individual motivation and thus facilitate recreational behavior. This awareness is dynamically evolving and it has been suggested that publicity and activities to encourage knowledge of UGS can be used as potential ways of the use promotion (Thompson et al., 2014). In addition, knowledge provides a means of explaining how social structure might influence the need of UGS recreation. For example, people who are well-educated or with high income might have better channels to gain this knowledge. Leisure preference represents the extent an individual likes the natural environment and/or outdoor recreation. Not enjoying exercise is reported as one barrier for partaking in UGS recreation (Lee and Maheswaran, 2011), while individuals' nature orientation would help to shape the need of UGS recreation (Lin et al., 2014).

\subsection{Enabling Resources - The Service Mobilization}

Recreational service is user movement related (Costanza, 2008). Even though the biophysical structure fit well with people's needs and a high level of recreational service potential is generated, the movement of people to UGS must occur to ensure the potential is transformed into a realized service. In this regard, people must have the means to enter in. Enabling component is proposed to describe factors influencing the mobilization process.

The enabling component is the resources that allow individuals to use UGS, and encompasses resources specific to individuals and attributes of the community where they live. Time and physical fitness are the main factors that constitute individual enabling resources. People may not choose to visit a park if they don't have enough time. Likewise, lack of physical fitness limiting mobility will impede UGS visits. Although most of UGS is open to public for free or low charges, it has been reported that residents with low incomes are sensitive to the cost (Scott and Munson, 1994). Indeed, lack of money might impede an individual to visit certain UGS. The money issue is not discussed in this section since we already have income as a social structure attribute under the predisposing component.

As for enabling conditions relating to community or environment, proximity and information of UGS are suggested. Firstly, UGS must be available where people live or work. The importance of distance to UGS or neighborhood greenness in facilitating the use of UGS has been well proved (see Section 2.4 for details). Secondly, certain information regarding UGS (like existence or location) should be known by people before their visit. Information constraints for potential UGS users, especially for those relying more on social networks to get access, may impede use and generate differences (Byrne and Wolch, 2009). In addition, parks have reputations reflecting their use, upkeep and design quality, which may be referred to by people for decision making. Interestingly, distance 
Table 1

Recommended indicators for measuring various components in the model.

\begin{tabular}{|c|c|c|c|c|}
\hline Category & Component & Sub-item & Indicator (example) & Way of access \\
\hline \multirow[t]{25}{*}{ UGS feature } & \multirow[t]{5}{*}{ Quantity } & & UGS area & Remote Sensing (RS) and Geographic \\
\hline & & & Green coverage rate & Information System (GIS) technology; \\
\hline & & & Water area & Design document review; \\
\hline & & & Number of UGS elements & Observer assessment. \\
\hline & & & Number of facilities & \\
\hline & \multirow[t]{3}{*}{ Distribution } & & Diversity index & RS technology and landscape metric \\
\hline & & & Evenness index & software such as FRAGSTAT (McGarigal \\
\hline & & & Dominance index & et al., 2012). \\
\hline & \multirow[t]{17}{*}{ Quality } & \multirow{11}{*}{$\begin{array}{l}\text { Structure } \\
\text { diversity }\end{array}$} & Proportion of natural vegetation area & RS and GIS technology; \\
\hline & & & Proportion of evergreen plants / flowering plants & Design document review; \\
\hline & & & Tree/shrub/herb species richness & Observer assessment \\
\hline & & & Level of vegetation succession & \\
\hline & & & Bird species richness & \\
\hline & & & Proportion of water area & \\
\hline & & & Presence of lake/river/fountain & \\
\hline & & & Presence of hill/slope & \\
\hline & & & Number of elements per area & \\
\hline & & & Presence of jogging path/playground & \\
\hline & & & Presence of amenities (bench, toilet, picnic table, shelter, pavilion and lighting) & \\
\hline & & \multirow[t]{6}{*}{ Stewardship } & Proportion of vegetation in different stages of abandonment & Observer assessment; \\
\hline & & & Density of weed & Management agency interview; \\
\hline & & & Presence of waste & Statistics review. \\
\hline & & & Condition of facilities & \\
\hline & & & Management frequency & \\
\hline & & & Number of crimes per area & \\
\hline \multirow{13}{*}{$\begin{array}{l}\text { Population } \\
\text { characteristics }\end{array}$} & \multirow{4}{*}{$\begin{array}{l}\text { Enabling } \\
\text { resources }\end{array}$} & \multirow{4}{*}{$\begin{array}{l}\text { Individual } \\
\text { enabling } \\
\text { Community } \\
\text { enabling }\end{array}$} & Hours of spare time per week & Self-report \\
\hline & & & Ratings of physical fitness & \\
\hline & & & Distance, travel time & GIS technology; \\
\hline & & & Number of informational programs & Management agency interview. \\
\hline & & Demographics & Age groups & Archives review \\
\hline & characteristics & & Male/Female & \\
\hline & & Social & Educational groups & Archives review; \\
\hline & & structure & Occupation groups & Self-report. \\
\hline & & & Income groups & \\
\hline & & & Cultural groups & \\
\hline & & & Religious groups & \\
\hline & & Knowledge & Knowledge scores & Standardized test assessment \\
\hline & & $\begin{array}{l}\text { Leisure } \\
\text { preference }\end{array}$ & Ratings of preference & Self-report \\
\hline Recreational use & Whether & & Yes/No & Self-report \\
\hline behavior & Where & & Site name & Self-report; \\
\hline & & & GPS coordinates & GPS technology. \\
\hline & What & Type and & Typology (Zhang et al., 2013): & Self-report \\
\hline & & intensity & 1. Jogging with/without other aerobic exercises and/or leisure activities & \\
\hline & & & 2. Aerobic exercises (without jogging) with/without leisure activities; & \\
\hline & & & 3. Walking with/without other leisure activities & \\
\hline & & & 4. Leisure activities only (without walking) & \\
\hline & & Social contact & Amount of social activities & Self-report; \\
\hline & & & Proportion of social to nonsocial activities & Observer assessment. \\
\hline & & & Likelihood of social interactions & \\
\hline & When & & Peak/Slack season & Self-report \\
\hline & & & Weekdays/Weekend/Public holiday & \\
\hline & & & Morning/day time/evening & \\
\hline & How often & & Cyclic/random/intermittent & Self-report \\
\hline & & & Visiting times in a period of time & \\
\hline & How long & & Hours per visit & Self-report \\
\hline Recreational & Physiological & Intermediate & Blood pressure & Biomarkers \\
\hline benefits & & outcome & Heart rate & \\
\hline & & & Heart rate variability & \\
\hline & & Final outcome & Body mass index (BMI) & Statistics review; \\
\hline & & & Chances of being overweight or obese & Self-report. \\
\hline & & & Morbidity of cardiovascular diseases & \\
\hline & & & Mortality of cardiovascular diseases & \\
\hline & & & Longevity & \\
\hline & Psychological & Intermediate & Frustration / anxiety level represented by number of complaints in a period of & Self-report; \\
\hline & & outcome & time & Standardized test assessment; \\
\hline & & & Score of self-esteem / mood / happiness level & Biomarkers. \\
\hline & & & Stress level represented by neuroendocrine changes characteristic, such as & \\
\hline & & & adrenaline, noradrenaline (Li et al., 2011), dopamine, salivary cortisol (Park et & \\
\hline & & & $\begin{array}{l}\text { al., 2010; Thompson et al., 2014; Ward Thompson et al., 2012) and telomere } \\
\text { (Woo et al., 2009). }\end{array}$ & \\
\hline & & Final outcome & General health status score & Assessed by standardized scales; \\
\hline & & & Anxiety and mood disorder treatment & Self-report; \\
\hline & & & Morbidity of mental disorder & Statistics review. \\
\hline & Social & & Neighborhood Social Ties (NSTs) (Kuo et al., 1998) & Assessed by standardized scales. \\
\hline & & & Sense of community (Kim and Kaplan, 2004) & \\
\hline
\end{tabular}


Table 1 (continued)

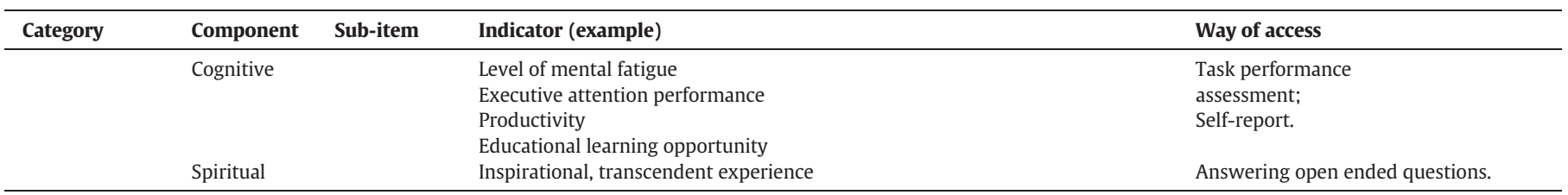

and information seem to have mixed effects. If an UGS is well known and preferred, distance is likely to be underestimated (Schipperijn et al., 2010b).

\subsection{Recreational Use Behavior and the Subsequent Benefits - The Realized Service}

\subsubsection{Recreational Use Behavior}

UGS recreational service is the result of the social system activating the service potential offered by UGS biophysical structure. It happens based on people-UGS contacts. In this sense, recreational behavior can be understood as a service carrier.

Recommended guideline for describing park use (Bedimo-Rung et al., 2005) suggests a two-step process: (1) visitation and (2) recreational activities within a park. The act of visiting is the first albeit the major step of the process of park recreation. Frequency, duration, type and intensity are used to describe recreational activities within UGS. What are missing from the guideline are temporal and spatial dimensions. Furthermore, we think that the type and intensity dimensions are overlapping as each type of activity is linked to certain physical intensity levels. Therefore, we suggest the understanding of recreational activities by answering questions from five dimensions--where, what, when, how long, and how often.

"Where" refers to the site that the recreational activities take place, implying a wide range of information like what type of UGS the site belongs to, how far it would be from home, and so on. "When" indicates time slots when individuals may visit the UGS. People may take advantage of different time slots to satisfy their diverse recreational needs, such as different seasons, workdays or holidays, and different times within a day (Jim and Chen, 2006; Lachowycz et al., 2012). "What" explains the activity types and intensity that visitors do in UGS. Lots of activities can be done in UGS, including jogging, walking, cycling, mediating, socializing, playing with kids and so on, each of which is linked to a certain intensity level. People usually do a combination of different types activities instead of focusing on only one. A taxonomy combining types and intensities is thus preferred. Here we adopted a taxonomy that is proposed by Zhang et al. (2013): (1) jogging with/ without other aerobic exercises ${ }^{1}$ and/or leisure activities ${ }^{2}$; (2) aerobic exercises (without jogging) with/without leisure activities; (3) walking with/without other leisure activities; (4) leisure activities only (without walking). The "how long" and "how often" describe the length of time (duration), the number of times and the pattern (including cyclic, random or intermittent) (frequency) an individual is exposed to UGS. A combination of duration, frequency and intensity of recreational activity, together with the intensity of UGS represented by its quantity and quality, form the foundation of measuring the "UGS dose" that individuals received, which enables the assessment of dose-response effect (Shanahan et al., 2015).

Unlike some studies, we do not regard "purpose" or "motivation" as recreational use behavior as they are not behaviors. Instead, "purposes" or "motivations" are factors that underpin the behavior, relating to the

\footnotetext{
${ }^{1}$ Examples of aerobic exercises are medium to long distance running/jogging, cycling, Nordic walking, mass fitness dancing, ball games, playing Taichi and so on

${ }^{2}$ Leisure activities are relatively relaxed activities including walking, fishing, playing musical instruments, sinning local opera, playing chess, photography, camping, chatting, reading, meditating, watching scenery and so on.
}

psychological aspect which has a close relationship with people's natural orientation.

\subsubsection{Recreational Benefits}

Recreational use of UGS is not only gaining recreational experiences but also a means to other ends and outcomes, i.e. making positive change in human well-being, known as recreational benefits (TEEB, 2010). When studying recreational service, it is important to examine it in the context of its benefits. Literature has summarized that exposure to UGS could have positive effect on public health, physiologically, cognitively, psychologically, socially and spiritually (Keniger et al., 2013). Psychological benefits are related to mental processes; physiological benefits are associated with physical function or physical health; social benefits refer to positive social effect on social cohesion; cognitive benefits are related to cognitive ability or function; and spiritual benefits are associated with people's religious pursuits or spiritual well-being (Keniger et al., 2013).

\section{Recreational Service Management}

The process of UGS recreational service generation flows down along the cascade to provide recreational benefits. In reverse, management interventions with objectives such as efficiency or equity can be inspired from reading this cascade reversely.

The concept of mutability is important in policy and management. Independent variables that can be altered by policy are regarded as "mutable", and those that cannot be changed by policy are labeled as "immutable". Only if a variable is found to be able to bring about behavioral changes (i.e. be able to explain use) and also be considered as mutable, can interventions that are viable be developed. Features of UGS (quantity, quality and distribution aspects) and community enabling resources (i.e. proximity and information) are regarded as being mutable. If studies showing these variables are able to explain the use of UGS, then interventions aim at regulating quantity, distribution or quality would be useful. Information campaigns also can be launched to make UGS better known, and with which increase their use. Knowledge regarding benefits of UGS use and being physically active can be enhanced through education propaganda programs (Heath et al., 2012; Thompson et al., 2014), and is therefore judged as having medium mutability. Preference towards nature or outdoor recreation is judged as low mutable since it is thought to be influenced by childhood experience (Jim and Shan, 2013; Lin et al., 2014) and thus may hardly be changed by policy interventions. Demographics, social structure, and individual enabling resources (time and physical fitness) are also judged as having low mutability, as age, gender, cultural background and religion are not changeable, and educational, occupational and income structure as well as spare time and physical fitness are probably not a feasible short-term policy to influence use.

Driven by the interest in enhancing public health and competing priorities for funding in health care, UGS recreational service management focuses on promoting the efficient use of UGS by regulating service potentials and their mobilization (shown by Fig. 1). This requires multisectoral approaches that are not only to figure out which interventions into biophysical structure of UGS are viable (physical planning guidelines), but also to include the necessity to shape the demand for the service (social strategies). At the population level, using UGS efficiently means to generate certain health benefits for the majority of the 
population at the lowest cost. This includes two steps. First, figuring out the minimum dose recommendation of UGS exposure for individuals (Shanahan et al., 2015). This would probably come out with several alternatives representing different combinations of the intensity, duration and frequency of recreational behaviors, and the quantity and quality of UGS that people exposed to. Second, linking those alternatives of the minimum dose to the specific interventions needed and the cost they may incur.

Equity is another important aspect that policy makers concern about. Literature has been exploring equity in UGS access by measuring its spatial availability, which, as what we've argued earlier, may lead to insufficient assessment result. Actually, research on health care service has accumulated abundant experiences and knowledge in assessing equity in the service access. The common practice of measuring has been to use utilization (the proof of access) as a proxy; the behavioral model of health service utilization (Andersen, 1968) provides an empirical approach to assessing the equity of health service utilization according to which predictors of use are dominant (Aday and Andersen, 2005). Specifically, equitable access is identified as occurring when variables related to an individual's need (from the demand side) determine who gets medical care, while inequitable access as occurring when differences in resources, either from the supply side (i.e. health care provider) or from the demand side (i.e. individuals), account for most of variances in utilization.

By drawing on the rationale that health care service adopted, equitable and inequitable access to UGS can be defined by which predictors of use are dominant. Equitable UGS access occurs when demographics (i.e. age and gender), preferences and individual enabling resources (i.e. time and physical fitness) determine who gets into UGS. Inequitable UGS access emerges when features of UGS, community enabling resources (i.e. distance/travel time), social structure (i.e. education, occupation, cultural background, religion and income) and knowledge account for most of variances in utilization. If studies show that inequitable access to UGS exists, variables that both cause the inequity and possess mutability can be seen as entry points for developing interventions to improve equity.

\section{Conduction of Empirical Studies/Assessments}

No matter with what management objectives, careful conduction of empirical studies/assessments is always important for delivering accurate and useful information for decision making. If we assume the robustness of conclusions as a continuous spectrum ranging from correlational relationship to the causal-effect, studies that are able to draw conclusions which are closer to the causal-effect end are more welcomed. To this end, certain survey design techniques can be used. Generally speaking, natural experiment design is better than the nonexperimental longitudinal, and the cross-sectional is the least preferred. Most cross-sectional studies adjusted their models for factors that may confound the results (such as socio-economic and demographic variables), however, this may not lead us to draw conclusions on the causality of relationships. The performance of the non-experimental longitudinal design is better as it enables us to adjust for the confounding factors by before-after comparisons. Yet, we are not able to guarantee all the possible confounding factors are properly controlled. Natural experimental design takes advantage of a natural event (such as a vacant lot greening program) as an experimental condition and then compares it to a control condition. By doing this, ideally, it is able to eliminate all the confounding factors. However, natural experimental studies at population level are hard to perform, and it will also be challenge to establish and maintain control sites or populations (Hartig et al., 2014).

Furthermore, the possibility of reverse causality may also confound results. People living in neighborhoods with better UGS may have chosen to live there because of a greater inclination to UGS recreation or better health (Frumkin, 2002). To address the issue of selective migration, instrumental variable (IV) approach that has been widely applied in economics may offer insights. The idea of IV approach is to find and use (an) extra variable(s) as instrument(s) in the regression so that the possibility of correlation between the explanatory variable and the error item can be eliminated. An eligible instrumental variable needs to meet the following requirements; it 1) has direct relationship with the explanatory variable, 2 ) doesn't have direct relationship with the dependent variable, and 3) doesn't have relationship with the error item. This approach is used to estimate causal relationships when controlled experiments are not feasible (Imbens and Angrist, 1994). For more information on this approach, interested readers may refer to almost every econometrics textbooks (Baum, 2006; Greene, 2008; Wooldridge, 2002).

Developing and validating a data collection tool would not be less important as adopting an appropriate study design. Table 1 shows recommended indicators measuring each constituent component in the model. By presenting the number of indicators and ways of access, we are hoping it could facilitate inclusion of multi-sectoral approaches in the conduction of empirical studies. However, assessments that fully implement the model in the process of urban land use planning require sufficient input of financial and human resources. Challenges exist especially when tight financial budget and reductions in staff and expertise in urban administration are happing (Kabisch, 2015). Against this context, who is able to do such a comprehensive assessment is worth pondering.

\section{Conclusion}

The current understanding of UGS recreational service are limited due to the lack of being examined under the logic that underlies the ecosystem service paradigm, leading to limitations in informing developing viable interventions to meet management objectives such as efficiency or equity. The conceptual model presented in this paper fills this knowledge gap and allows for more comprehensive and accurate applications to the ecosystem based management in urban land use planning.

The model encompasses UGS features, population characteristics, recreational use behaviors and recreational benefits as four categories while considering the use behavior as the service carrier. In the process of generating the service, people first recognize the potential usability of certain UGS features (biophysical structure) that constitute an ecosystem service potential; the potential would then be mobilized by facilitating movements of people to UGS to provide recreational service and generate benefits. The important roles of regulating service potentials and their mobilization have been highlighted, and multi-sectoral approaches are required.

Interventions to improve efficient use can be informed by figuring out the minimum dose recommendation of exposure to UGS corresponding to certain health response, and by linking possible management actions to their cost. On the other hand, interventions to improve equity in UGS access can be informed by exploring which predictors of use are dominant. This new way of measuring advances UGS access assessment by shifting the spatial-based to the use-based, which paves a promising avenue for future research.

To assure the accuracy of information that assessments provide, certain survey design techniques are recommended, among which, the natural experimental study at population level is the most welcomed. A summary of the indicators measuring variables of the model is presented to facilitate assessments. The model is well developed; however, with numerous indicators that need to be collected and constraints confronted by urban administration in many cities, how the full application of this model work is a real challenge at practice level.

Lastly, one limitation of the paper is that the model has not been tested by data. However, we believe that the development of this model will provide insightful guidance for empirical studies, and its application will be an important area for our future research. 


\section{Acknowledgments}

The authors are indebted to their fellow colleagues at the UNEP_ International Ecosystem Management Partnership (UNEP-IEMP), in particular Ms. Karen Mrema, Dr. Min Jet Loo for their insights and expertise, as well as friends Dr. Daiyue Huang, Mr. Sai Chen and Ms. Na Chen. Special thanks to Dr. Linxiu Zhang for her continuous supports and valuable guidance during the drafting of this paper.

We acknowledge the financial support of the National Natural Science Foundation of China (grant no.31361140360).

\section{References}

Aday, L.A., Andersen, R.M., 2005. Health Care Utilization and Behavior, Models of, Encyclopedia of Biostatistics. John Wiley \& Sons, Ltd.

Adinolfi, C., Suárez-Cáceres, G.P., Cariñanos, P., 2014. Relation between visitors' behaviour and characteristics of green spaces in the city of Granada, South-Eastern Spain. Urban For. Urban Green. 13, 534-542.

Andersen, R.M., 1968. Famlies' Use of Health Services: A Behavior Model of Predisposing, Enabling, and Need Components. Purdue University, Ann Arbor, p. 274-274.

Baum, C.F., 2006. An Introduction to Modern Econometrics Using Stata. Stata Press, College Station, Texas

Bedimo-Rung, A.L., Mowen, A.J., Cohen, D.A., 2005. The significance of parks to physical activity and public health: a conceptual model. Am. J. Prev. Med. 28, 159-168.

Bird, W., 2004. Can green space and biodiversity increase levels of physical activity?

Branas, C.C., Cheney, R.A., MacDonald, J.M., Tam, V.W., Jackson, T.D., Ten Have, T.R., 2011 A difference-in-differences analysis of health, safety, and greening vacant urban space. Am. J. Epidemiol. 174, 1296-1306.

Brower, S., Dockett, K., Taylor, R.B., 1983. Residents' perceptions of territorial features and perceived local threat. Environ. Behav. 15, 419-437.

Byrne, J., Wolch, J., 2009. Nature, race, and parks: past research and future directions for geographic research. Prog. Hum. Geogr. 33, 743-765.

Byrne, J., Wolch, J., Zhang, J., 2009. Planning for environmental justice in an urban national park. J. Environ. Plan. Manag. 52, 365-392.

Carpenter, M., 2013. From 'healthful exercise' to 'nature on prescription': the politics of urban green spaces and walking for health. Landsc. Urban Plan. 118, 120-127.

Chan, K.M.A., Satterfield, T., Goldstein, J., 2012. Rethinking ecosystem services to better address and navigate cultural values. Ecol. Econ. 74, 8-18.

Clark, N.E., Lovell, R., Wheeler, B.W., Higgins, S.L., Depledge, M.H., Norris, K., 2014. Biodiversity, cultural pathways, and human health: a framework. Trends Ecol. Evol. 29 198-204.

Cohen, D.A., Ashwood, J.S., Scott, M.M., Overton, A., Evenson, K.R., Staten, L.K., Porter, D., McKenzie, T.L., Catellier, D., 2006. Public parks and physical activity among adolescent girls. Pediatrics 118, 1381-1389.

Cohen, D.A., McKenzie, T.L., Sehgal, A., Williamson, S., Golinelli, D., Lurie, N., 2007. Contribution of public parks to physical activity. Am. J. Public Health 97, 509-514.

Comber, A., Brunsdon, C., Green, E., 2008. Using a GIS-based network analysis to determine urban green space accessibility for different ethnic and religious groups. Landsc. Urban Plan. 86, 103-114.

Coombes, E., Jones, A.P., Hillsdon, M., 2010. The relationship of physical activity and overweight to objectively measured green space accessibility and use. Soc. Sci. Med. 70, $816-822$.

Costanza, R., 2008. Ecosystem services: multiple classification systems are needed. Biol. Conserv. 141, 350-352.

Coutts, C.J., 2010. Public health ecology. J. Environ. Health 72, 53-55.

Coutts, C., Forkink, A., Weiner, J., 2014. The portrayal of natural environment in the evolution of the ecological public health paradigm. Int. J. Environ. Res. Public Health 11 $1005-1019$.

Dai, D., 2011. Racial/ethnic and socioeconomic disparities in urban green space accessibility: where to intervene? Landsc. Urban Plan. 102, 234-244.

Dallimer, M., Irvine, K.N., Skinner, A.M.J., Davies, Z.G., Rouquette, J.R., Maltby, L.L., Warren, P.H., Armsworth, P.R., Gaston, K.J., 2012. Biodiversity and the feel-good factor: understanding associations between self-reported human well-being and species richness. Bioscience 62, 47-55.

Dallimer, M., Davies, Z.G., Irvine, K.N., Maltby, L., Warren, P.H., Gaston, K.J., Armsworth, P.R., 2014. What personal and environmental factors determine frequency of urban greenspace use? Int. J. Environ. Res. Public Health 11, 7977-7992.

DTLR, 2002. Green spaces, Better Places. Final Report of the Urban Green Spaces Taskforce. Department of Transport, Local Government and Regions, London.

Ellaway, A., Macintyre, S., Bonnefoy, X., 2005. Graffiti, greenery, and obesity in adults: secondary analysis of European cross sectional survey. BMJ 331, 611-612.

Evenson, K.R., Wen, F., Hillier, A., Cohen, D.A., 2013. Assessing the contribution of parks to physical activity using GPS and accelerometry. Med. Sci. Sports Exerc. 45, 1981-1987.

Fish, R.D., 2011. Environmental decision making and an ecosystems approach: some challenges from the perspective of social science. Prog. Phys. Geogr. 35, 671-680.

Frumkin, H., 2002. Urban sprawl and public health. Public Health Rep. 117, 201-217.

Fuller, R.A., Irvine, K.N., Devine-Wright, P., Warren, P.H., Gaston, K.J., 2007. Psychological benefits of greenspace increase with biodiversity. Biol. Lett. 3, 390-394.

Giles-Corti, B., Broomhall, M.H., Knuiman, M., Collins, C., Douglas, K., Ng, K., Lange, A Donovan, R.J., 2005. Increasing walking: how important is distance to, attractiveness, and size of public open space? Am. J. Prev. Med. 28, 169-176.
Gladwell, V.F., Brown, D.K, Wood, C., Sandercock, G.R, Barton, J.L, 2013. The great outdoors: how a green exercise environment can benefit all. Extreme Physiol. Med. 2, 3. Grahn, P., Stigsdotter, U.A., 2003. Landscape planning and stress. Urban For. Urban Green. 2, 1-18.

Granek, E.F., Polasky, S., Kappel, C.V., Reed, D.J., Stoms, D.M., Koch, E.W., Kennedy, C.J., Cramer, L.A., Hacker, S.D., Barbier, E.B., Aswani, S., Ruckelshaus, M., Perillo, G.M., Silliman, B.R., Muthiga, N., Bael, D., Wolanski, E., 2010. Ecosystem services as a common language for coastal ecosystem-based management. Conserv. Biol. 24, 207-216.

Greene, W.H., 2008. Econometric Analysis. Prentice Hall, Upper Saddle River, NJ.

Hagerhall, C.M., Purcell, T., Taylor, R., 2004. Fractal dimension of landscape silhouette outlines as a predictor of landscape preference. J. Environ. Psychol. 24, 247-255.

Haines-Young, R., Potschin, M., 2010. The Links Between Biodiversity, Ecosystem Services and Human Well-Being. Cambridge University Press, Cambridge.

Hartig, T., Mitchell, R., Vries, S.d., Frumkin, H., 2014. Nature and health. Annu. Rev. Public Health 35, 207-228.

Heath, G.W., Parra, D.C., Sarmiento, O.L., Andersen, L.B., Owen, N., Goenka, S., Montes, F., Brownson, R.C., 2012. Evidence-based intervention in physical activity: lessons from around the world. Lancet 380, 272-281.

Hug, S.-M., Hartig, T., Hansmann, R., Seeland, K., Hornung, R., 2009. Restorative qualities of indoor and outdoor exercise settings as predictors of exercise frequency. Health Place $15,971-980$

Imbens, G.W., Angrist, J.D., 1994. Identification and estimation of local average treatment effects. Econometrica 62, 467-475.

Irvine, K., Warber, S., Devine-Wright, P., Gaston, K., 2013. Understanding urban green space as a health resource: a qualitative comparison of visit motivation and derived effects among park users in Sheffield, UK. Int. J. Environ. Res. Public Health 10, 417-442.

Jim, C.Y., Chen, W.Y., 2006. Recreation-amenity use and contingent valuation of urban greenspaces in Guangzhou, China. Landsc. Urban Plan. 75, 81-96.

Jim, C.Y., Shan, X., 2013. Socioeconomic effect on perception of urban green spaces in Guangzhou, China. Cities 31, 123-131.

Kabisch, N., 2015. Ecosystem service implementation and governance challenges in urban green space planning-the case of Berlin, Germany. Land Use Policy 42, 557-567.

Kappel, C.V., Martone, R.G., 2011. Ecosystem-based management. at: http://www. eoearth.org/view/article/152249/ (accessed by 12/12/2015).

Keniger, L.E., Gaston, K.J., Irvine, K.N., Fuller, R.A., 2013. What are the benefits of interacting with nature? Int. J. Environ. Res. Public Health 10, 913-935.

Kim, J., Kaplan, R., 2004. Physical and psychological factors in sense of community: new urbanist Kentlands and nearby Orchard Village. Environ. Behav. 36, 313-340.

Kuo, F., Sullivan, W., Coley, R., Brunson, L., 1998. Fertile ground for community: inner-city neighborhood common spaces. Am. J. Community Psychol. 26, 823-851.

Lachowycz, K., Jones, A.P., Page, A.S., Wheeler, B.W., Cooper, A.R., 2012. What can global positioning systems tell us about the contribution of different types of urban greenspace to children's physical activity? Health Place 18, 586-594.

LaGrange, R.L., Ferraro, K.F., Supancic, M., 1992. Perceived risk and fear of crime: role of social and physical incivilities. J. Res. Crime Delinq. 29, 311-334.

Landry, S.M., Chakraborty, J., 2009. Street trees and equity: evaluating the spatial distribution of an urban amenity. Environ. Plan. A 41, 2651-2670.

Lee, A.C.K., Maheswaran, R., 2011. The health benefits of urban green spaces: a review of the evidence. J. Public Health 33, 212-222.

Li, Q., Otsuka, T., Kobayashi, M., Wakayama, Y., Inagaki, H., Katsumata, M., Hirata, Y., Li, Y., Hirata, K., Shimizu, T., Suzuki, H., Kawada, T., Kagawa, T., 2011. Acute effects of walking in forest environments on cardiovascular and metabolic parameters. Eur. J. Appl. Physiol. 111, 2845-2853.

Lin, B.B., Fuller, R.A., Bush, R., Gaston, K.J., Shanahan, D.F., 2014. Opportunity or orientation? Who uses urban parks and why. PLoS One 9, e87422.

MA, 2005. Ecosystems and human well-being: biodiversity synthesis. World Resources Institute, Washington, DC

Matthew McConnachie, M., Shackleton, C.M., 2010. Public green space inequality in small towns in South Africa. Habitat Int. 34, 244-248.

McCormack, G.R., Rock, M., Toohey, A.M., Hignell, D., 2010. Characteristics of urban parks associated with park use and physical activity: a review of qualitative research. Health Place 16, 712-726.

McGarigal, K., Cushman, S., Ene, E., 2012. FRAGSTATS V4: spatial pattern analysis program for categorical and continuous maps. Computer Software Program Produced by the Authors the University of Massachusetts, Amherst.

McIntyre, D.I., Thiede, M., Birch, S., 2009. Access as a policy-relevant concept in low- and middle-income countries. Health Econ. Policy Law 4, 179-193.

Milcu, A.I., Hanspach, J., Abson, D., Fischer, J., 2013. Cultural ecosystem services: a literature review and prospects for future research. Ecol. Soc. 18

Nielsen, T.S., Hansen, K.B., 2007. Do green areas affect health? Results from a Danish survey on the use of green areas and health indicators. Health Place 13, 839-850.

Ode, Å., Tveit, M.S., Fry, G., 2008. Capturing landscape visual character using indicators: touching base with landscape aesthetic theory. Landsc. Res. 33, 89-117.

Ode, A., Fry, G., Tveit, M.S., Messager, P., Miller, D., 2009. Indicators of perceived naturalness as drivers of landscape preference. J. Environ. Manag. 90, 375-383.

Park, B., Tsunetsugu, Y., Kasetani, T., Kagawa, T., Miyazaki, Y., 2010. The physiological effects of Shinrin-yoku (taking in the forest atmosphere or forest bathing): evidence from field experiments in 24 forests across Japan. Environ. Health Prev. Med. 15, 18-26.

Penchansky, R., Thomas, J.W., 1981. The concept of access: definition and relationship to consumer satisfaction. Med. Care 19, 127-140.

Potschin, M.B., Haines-Young, R.H., 2011. Ecosystem services: exploring a geographical perspective. Prog. Phys. Geogr. 35, 575-594.

Schipperijn, J., Ekholm, O., Stigsdotter, U.K., Toftager, M., Bentsen, P., Kamper-Jørgensen, F., Randrup, T.B., 2010a. Factors influencing the use of green space: results from a Danish national representative survey. Landsc. Urban Plan. 95, 130-137. 
Schipperijn, J., Stigsdotter, U.K., Randrup, T.B., Troelsen, J., 2010b. Influences on the use of urban green space - a case study in Odense, Denmark. Urban For. Urban Green. 9 , 25-32.

Schipperijn, J., Bentsen, P., Troelsen, J., Toftager, M., Stigsdotter, U.K., 2013. Associations between physical activity and characteristics of urban green space. Urban For. Urban Green. 12, 109-116.

Scott, D., Munson, W., 1994. Perceived constraints to park usage among individuals with low incomes. J. Park. Recreat. Adm. 12 (4), 79-96.

Shanahan, D.F., Fuller, R.A., Bush, R., Lin, B.B., Gaston, K.J., 2015. The health benefits of urban nature: how much do we need? Bioscience.

Smith, T., Nelischer, M., Perkins, N., 1997. Quality of an urban community: a framework for understanding the relationship between quality and physical form. Landsc. Urban Plan. 39, 229-241.

Spangenberg, J.H., von Haaren, C., Settele, J., 2014. The ecosystem service cascade: further developing the metaphor. integrating societal processes to accommodate social processes and planning, and the case of bioenergy. Ecol. Econ. 104, 22-32.

TEEB, 2010. The Economics of Ecosystems and Biodiversity (TEEB): Ecological and Economic Foundations. Earthscan, London.

Thompson, C.W., Aspinall, P., Roe, J., 2014. Access to green space in disadvantaged urban communities: evidence of salutogenic effects based on biomarker and self-report measures of wellbeing. Procedia Soc. Behav. Sci. 153, 10-22.

Tveit, M., Ode, Å., Fry, G., 2006. Key concepts in a framework for analysing visual landscape character. Landsc. Res. 31, 229-255.

Tzoulas, K., Korpela, K., Venn, S., Yli-Pelkonen, V., Kaźmierczak, A., Niemela, J., James, P., 2007. Promoting ecosystem and human health in urban areas using green infrastructure: a literature review. Landsc. Urban Plan. 81, 167-178.

Van Herzele, A., Wiedemann, T., 2003. A monitoring tool for the provision of accessible and attractive urban green spaces. Landsc. Urban Plan. 63, 109-126.

VanLeeuwen, J.A., Waltner-Toews, D., Abernathy, T., Smit, B., 1999. Evolving models of human health toward an ecosystem context. Ecosyst. Health 5, 204-219.

Veitch, J., Ball, K., Crawford, D., Abbott, G.R., Salmon, J., 2012. Park improvements and park activity: a natural experiment. Am. J. Prev. Med. 42, 616-619.

Villeneuve, P.J., Jerrett, M., Su, J.G., Burnett, R.T., Chen, H., Wheeler, A.J., Goldberg, M.S 2012. A cohort study relating urban green space with mortality in Ontario, Canada. Environ. Res. 115, 51-58.
Voigt, A., Kabisch, N., Wurster, D., Haase, D., Breuste, J., 2014. Structural diversity: a multidimensional approach to assess recreational services in urban parks. Ambio 43, 480-491.

Wallace, K.J., 2007. Classification of ecosystem services: problems and solutions. Biol. Conserv. 139, 235-246.

Ward Thompson, C., Roe, J., Aspinall, P., Mitchell, R., Clow, A., Miller, D., 2012. More green space is linked to less stress in deprived communities: evidence from salivary cortisol patterns. Landsc. Urban Plan. 105, 221-229.

Ward, C.D., Parker, C.M., Shackleton, C.M., 2010. The use and appreciation of botanical gardens as urban green spaces in South Africa. Urban For. Urban Green. 9, 49-55.

West, S.T., Shores, K.A., Mudd, L.M., 2012. Association of available parkland, physical activity, and overweight in America's largest cities. J. Public Health Manag. Pract. 18, 423-430.

Wheeler, B.W., Lovell, R., Higgins, S.L., White, M.P., Alcock, I., Osborne, N.J., Husk, K., Sabel, C.E., Depledge, M.H., 2015. Beyond greenspace: an ecological study of population general health and indicators of natural environment type and quality. Int. J. Health Geogr. 14, 17.

White, M.P., Alcock, I., Wheeler, B.W., Depledge, M.H., 2013. Would you be happier living in a greener urban area? A fixed-effects analysis of panel data. Psychol. Sci. 24 920-928.

Wolch, J., Wilson, J.P., Fehrenbach, J., 2005. Parks and park funding in Los Angeles: an equity-mapping analysis. Urban Geogr. 26, 4-35.

Woo, J., Tang, N., Suen, E., Leung, J., Wong, M., 2009. Green space, psychological restoration, and telomere length. Lancet 373, 299-300.

Wooldridge, J.M., 2002. Econometric Analysis of Cross Section and Panel Data. MIT Press, Cambridge, Mass.

Zhang, X., Lu, H., Holt, J.B., 2011. Modeling spatial accessibility to parks: a national study. Int. J. Health Geogr. 10, 31.

Zhang, H., Chen, B., Sun, Z., Bao, Z., 2013. Landscape perception and recreation needs in urban green space in Fuyang, Hangzhou, China. Urban For. Urban Green. 12, 44-52. 